\title{
The effect of crude oil on the biochemical parameters of the blood of white rats
}

\author{
Alibek Ydyrys ${ }^{1,2, *}$, Nurzhaniyat Ablaikhanova ${ }^{1}$, Balgyn Amanbay ${ }^{1}$, Kalamkas Seiykadyr $^{1}$, \\ and Dana Demeuova ${ }^{1}$ \\ ${ }^{1}$ Al-Farabi Kazakh National University, 71 al-Farabi Ave. 050040 Almaty, Kazakhstan \\ ${ }^{2}$ Biomedical Research Centre Al-Farabi Kazakh National University, 71 al-Farabi Ave. 050040 \\ Almaty, Kazakhstan
}

\begin{abstract}
In this article authors were identified the effect of crude oil on the biochemical parameters of white rat blood. The experiments were conducted in two groups. In the first group, biochemical blood parameters of the control group were determined. In the second group, the biochemical parameters of the blood of white rats after poisoning with crude oil were determined: during the experiment, white rats were treated for chronic crude oil poisoning. Crude oil products from the Zhanaozen oil field were the main food for white rats. Feeding of white rats was carried out according to commonly used methods. The oil concentration in the feed is about $1 \%$. There was also a weak concentration of oil in the water of $0.001 \%$. Thus, rats were fed a daily dose of $5.85 \mathrm{~g}$ of oil per day. Results: The results of the study show a decrease in the mechanical properties of oil-poisoned organisms in stem cells and the intensity of protein synthesis. Leads to metabolic processes and physiological changes in the body. Biochemical parameters of the blood of white rats after poisoning with crude oil indicate impaired liver and kidney function. Based on the results of the study, it can be concluded that crude oil has a high negative impact on the biochemical parameters of the blood and causes various diseases. Therefore, the results of the study can be used to organize measures to protect the environment and animal and human health in oil-producing areas.
\end{abstract}

\section{Introduction}

One of the reasons for the serious influence of the environment on the anthropogenic activities are the impact of a huge amount of toxic substances [1]. Anthropogenic and technological impact on the environment is reflected not only in environmental pollution, but also in the reduction of the number of species in biodiversity $[2,3]$, the decline of natural populations [4], the extinction of endemic and rare species [5,6]. Toxins are exposed to humans through inhaled air, food, and water intake, and through the skin. Oil entering the body of animals can cause gastrointestinal bleeding, liver toxicity, kidney failure and blood pressure disorders [7]. In addition, oil vaporization in a large spill, or in

\footnotetext{
* Corresponding author: ydyrys.alibek@gmail.com
} 
the immediate vicinity of it, is also detrimental to mammals. To normalize the disturbed metabolic processes in the body of animals caused by anthropogenic ecotoxicants, quite a lot of different means and methods have been proposed (antagonists of heavy metals, adsorbents, premixes, and feed additives). Enterosorbents are an effective means of reducing the negative effects of ecotoxicants on the animal organism. Enterosorption practically has no contraindications, does not require special equipment, and is applicable in any conditions.

The oil industry is now quite rightly attributed to those industries that are most responsible for the pollution of the environment. The imperfection of technologies for the extraction, transport and refining of oil leads to its systematic release into the environment. To an even greater extent, this is facilitated by the growth of accidents in oil production operations due to the severe wear of special equipment. When oil and oil products enter water bodies, an oil film forms on the surface of the water, which significantly disrupts the natural exchange of energy, heat, gases, moisture between the atmosphere and water bodies', which negatively affects the processes of natural self-purification of water bodies and their inhabitants. If oil gets into the soil, it destroys its structure and disrupts the normal growth of plants for a few years $[8,9]$.

In order to timely identify pathological deviations under the action of environmentally unfavorable factors, which include oil pollution of the environment, it is necessary to use informative methods of analysis that allow quickly assessing the activity of the body's protective functions, its reserve capabilities, the degree of reaction of various systems to the action of extreme factors. At present, it can be considered established that the initial period of extreme influences is accompanied by an emergency mobilization of physiological mechanisms that do not depend on the nature of the stimulus. This made it possible to call such mechanisms non-specific. They are based on blood. The blood system participates in the integration of the organismic response along with the central nervous system and humoral regulators [10]. Blood prevents disturbances in energetic, structural, acid-base and other types of homeostasis, provides a reaction of resistance to sudden changes in metabolism. Blood phagocytes together with tissue analogues cleanse the body of toxic substances, damaged cells, their fragments, and decay products. Erythrocytes and leukocytes acquire the importance of an organismic system of homeostatic regulation, which determines the body's ability to resist the effects of oil pollution and recover. This makes the problem of studying oil pollution on the organism of animals and humans urgent [11].

\section{Materials and Methods}

Experiments to fulfill the goals and objectives of the research work were carried out at the Department of Biophysics and Biomedicine and the Research Center of Biomedicine of AlFarabi KazNU.

\subsection{Research materials}

As a material for the study, the weight of 8 months was 150-200 g. The laboratory obtained 60 white rats. The animals were bred in vivarium. The experiments were conducted in two batches. In the first batch, biochemical and hematological parameters of the control group were determined. In the second batch, the biochemical and hematological parameters of the blood of white rats after poisoning with crude oil were determined. The effect of crude oil was studied: Group I - control group; Group II (10 days), Group III (20 days), Group IV (30 days).

In the laboratory, a study was conducted to poison normal white rats with crude oil 
products. During the experiment, white rats were exposed to chronic crude oil poisoning.

The main food for white rats was crude oil products from the Zhanaozen oil field. $36 \%$ are described accordingly. This type of oil contains less apoptotic carbon and, in particular, less toxic monocyclic carbon. The control group was fed water and food in the same proportions as in the experimental group, but without oil. The oil concentration in the feed is about $1 \%$. There was also a weak concentration of oil in the water of $0.001 \%$. Thus, rats were fed a daily dose of $5.85 \mathrm{~g}$ of oil per day.

Practical work on this method was carried out in two stages. The practical work lasted for 60 days. The experiments were carried out according to the generally accepted standard. At the end of the experiment, all other animals were killed.

Significant changes in the biochemical and hematological parameters of the blood of rats poisoned by crude oil were observed in comparison with the control group. There was a decrease in all parameters of biochemical parameters. Several deviations in hematological parameters were revealed.

\subsection{Methods of laboratory blood tests}

Determination of biochemical parameters of blood Biochemical parameters were determined in the analyzer Biochem SA, (HTI, USA). Collection of blood from laboratory animals was carried out by the method of decapitation. Approximately $0.5-0.6 \mathrm{ml}$ of blood can be obtained from rats by decapitation. Before decapitation, the animals were put to sleep with chlorophyll. Put in a centrifuge for 20 minutes and get the readings with a biochemical apparatus. The biochemical device detects fluctuations in biochemical parameters.

\section{Results and discussion}

The experiments were conducted in two batches. In the first set, the control group was identified, and in the second set, the biochemical parameters of the animal's blood when exposed to crude oil were determined.

Table 1. Biochemical parameters of normal and oil-poisoned white rat blood

\begin{tabular}{|c|c|c|c|}
\hline Indeices & Normal indicator & $\begin{array}{l}\text { Group I (control group), } \mathrm{n}= \\
12\end{array}$ & $\begin{array}{l}\text { Group II (in case } \\
\text { of oil poisoning), } \mathrm{n} \\
=12\end{array}$ \\
\hline Total protein, $g \backslash 1$ & $66-87$ & $67,3 \pm 0,04$ & $89,1 \pm 0,05$ \\
\hline Glucose, $\mathrm{mol} / \mathrm{l}$ & $8,8-16,3$ & $9,2 \pm 0,05$ & $17,6 \pm 0,05$ \\
\hline urea, $\mathrm{mmol} \backslash 1$ & $2,3-8,3$ & $6,4 \pm 0,03$ & $10,4 \pm 0,03$ \\
\hline creatinin, $\mathrm{mmol} \backslash 1$ & $45-115$ & $62,1 \pm 0,04$ & $116,2 \pm 0,08$ \\
\hline ALT (IU) & $110,0-140,0$ & $123,0 \pm 0,07$ & $156 \pm 0,05$ \\
\hline AST (IU) & $72,0-196,0$ & $93,2 \pm 0,05$ & $213 \pm 0,07$ \\
\hline Total bilirubin , $\mathrm{mmol} \backslash 1$ & $22,2-35,6$ & $36,7 \pm 0,03$ & $31,4 \pm 0,04$ \\
\hline Direct bilirubin, $\mathrm{mmol} \backslash 1$ & $5,1-8,2$ & $6,2 \pm 0,04$ & $2,16 \pm 0,05$ \\
\hline Cholesterol, $\mathrm{mmol} \backslash 1$ & $2,2-2,6$ & $2,4 \pm 0,03$ & $3,1 \pm 0,04$ \\
\hline
\end{tabular}

We mix crude oil products into the rats' food, monitor them for twenty-four hours, and compare their thirty-day biochemical parameters. Decapitation was performed to obtain pure blood from rats. Approximately $0.5-0.6 \mathrm{ml}$ of blood can be obtained from rats by decapitation. Before decapitation, the animals are put to sleep with chlorophyll, placed in a 
centrifuge for twenty minutes and taken with a biochemical device. We compare the blood values by repeated experiments with a biochemical apparatus (Table 1). Biochemical parameters of rats in the control group (Table 1) were total protein $67.3 \pm 0.04$, urine $6.4 \pm$ 0.03 , creatinine $62.1 \pm 0.04$, and ALT $123.0 \pm 0.07$, AST $93.2 \pm 0.05$, total bilirubin $36.7 \pm$ 0.03 , direct bilirubin $6.2 \pm 0.04$, cholesterol $2.4 \pm 0.03$. There were no deviations in the control group compared to normal. Biochemical parameters of white rats poisoned by crude oil (Table 1) increased total protein $89.1 \pm 0.05$, glucose $17.6 \pm 0.05$, urine $10.4 \pm 0.03$, creatinine $116.2 \pm 0.08$ As a result, the liver shows impaired renal function, resulting in changes in the kidneys.

We mix crude oil products into the rats' food, monitor them for twenty-four hours, and compare their thirty-day biochemical parameters. Decapitation was performed to obtain pure blood from rats. Approximately $0.5-0.6 \mathrm{ml}$ of blood can be obtained from rats by decapitation. Before decapitation, the animals are put to sleep with chlorophyll, placed in a centrifuge for twenty minutes and taken with a biochemical device. We compare the blood values by repeated experiments with a biochemical apparatus (Table 1).

Biochemical parameters of rats in the control group (Table 1) were total protein $67.3 \pm$ 0.04 , urine $6.4 \pm 0.03$, creatinine $62.1 \pm 0.04$, and ALT $123.0 \pm 0.07$, AST 93.2 \pm 0.05 , total bilirubin $36.7 \pm 0.03$, direct bilirubin $6.2 \pm 0.04$, cholesterol $2.4 \pm 0.03$. There were no deviations in the control group compared to normal. Biochemical parameters of white rats poisoned by crude oil (Table 1) increased total protein $89.1 \pm 0.05$, glucose $17.6 \pm 0.05$, urine $10.4 \pm 0.03$, creatinine $116.2 \pm 0.08$ As a result, the liver shows impaired renal function, resulting in changes in the kidneys. Biochemical parameters of crude oil-poisoned white rats (Table 1) increased total protein $89.1 \pm 0.05$, glucose $17.6 \pm 0.05$, urine $10.4 \pm$ 0.03 , creatinine $116.2 \pm 0.08$ As a result, the liver shows impaired renal function, resulting in changes in the kidneys. $75-85 \%$ of bilirubin is formed during the breakdown of hemoglobin in erythrocytes. The remaining $15-25 \%$ is formed from non-erythrocyte heme (myoglobin, cytochromes). Up to $1 \%$ of erythrocytes per day in the body, in the reticuloendothelial system, break down, and about $7.5 \mathrm{~g}$ of hemoglobin is released. Hemoglobin is divided into heme and globin. Heme forms bilirubin in the next oxidation cycle. $34 \mathrm{~g}$ of bilirubin is formed from $1 \mathrm{~g}$ of hemoglobin. The process of conversion of heme into bilirubin takes place in the cytoplasmic network of cells and they are closely related to each other. Bilirubin is converted to bilirubin by the action of bilirubin reductase in the cytoplasm of the cell.

This bilirubin is free bilirubin, which is released from macrophages and enters the bloodstream. Free bilirubin in the blood binds to albumin (1g of albumin binds to 14.4 $\mu \mathrm{mol} / 1$ of bilirubin), which is unconjugated or indirect bilirubin. This bilirubin does not affect brain tissue, the development of encephalopathy, does not pass through the glomerular membranes. Bilirubin, which is not bound to albumin, binds to phospholipids in brain tissue and enters the cell. It affects the nucleus in the cell and causes irreversible changes. The amount of free bilirubin in the blood is normal, not more than one percent, and the amount of albumin in $100 \mathrm{ml}$ of plasma is not less than $3 \mathrm{~g}$. When the amount of albumin decreases, the level of free bilirubin in the blood serum increases. Because bilirubin can pass through the hepatocyte membrane in both directions, bilirubin in the liver breaks the link with albumin.

Enzymes alanine aminotransferase (ALT), aspartate aminotransferase (AST) provide normal intrahepatic metabolism. And their increase in the blood may be due to the breakdown of hepatocytes (viral or chronic hepatitis). For example, the cause of jaundice is also due to excessive breakdown of red blood cells. In this case, along with anemia (anemia), the presence of antibodies against red blood cells (autoimmune hemolysis) or changes in the osmotic properties of blood cells (erythrocytes) were detected. 
The term hypertension is used to describe an increase in blood pressure. Increased blood pressure begins with narrowing of the blood vessel or its small branches. High blood pressure also depends on the amount of fat you use. Fats that are absorbed with food, especially fat, are dangerous to increase cholesterol levels. Cholesterol is synthesized in your body even if you do not eat it at all. Of course, the more fatty, fried foods you eat, the higher your cholesterol. Without cholesterol, our body would be in a difficult situation, because it is present in every cell: Cholesterol is involved in the construction of nerve fibers in the brain; it helps calcium be absorbed into the bones and makes them stronger; Cholesterol is a source of energy, tightening heart muscle cells; Cholesterol, which provides vitamin D3, makes the skin smooth and soft; Cholesterol in the liver affects the formation of new cells; is the basis for the synthesis of sex hormones. Therefore, the rise in cholesterol causes several abnormalities in the body. Since the total protein in the biochemical parameters of crude oil-poisoned rats is a yellow pigment in the blood, an increase or decrease in this pigment is similar to liver dysfunction, urinary incontinence in case of creatinine abnormalities, and creatinine is excreted by the kidneys. comes out. An increase or decrease in creatinine leads to kidney disease, while total protein determines the protein content of serum in the blood. ALT, AST are enzymes that determine liver function.

\section{Conclusion}

The results of the study show a decrease in the mechanical properties of oil-poisoned organisms in stem cells and the intensity of protein synthesis. Leads to metabolic processes and physiological changes in the body: Biochemical parameters of the blood of white rats after poisoning with crude oil indicate impaired liver and kidney function.

\section{References}

1. Poonam, Renu Bhardwaj, Resham Sharma, Neha Handa, Harpreet Kaur, Ravdeep Kaur, Geetika Sirhindi, A.K. Thukral, Emerging Technologies and Management of Crop Stress Tolerance, 2, 449 (2014)

2. E.A. Bukenova, Zh.M. Bassygarayev, A.B. Akhmetova, Zh.K. Zhunusbayeva, A. Ydyrys, Development of the Method of Obtaining the Endogenic Biostimulator from Wheat Green Spike Glumes Research on Crops, 20(1), 210 (2019) DOI: $10.31830 / 2348-7542.2019 .030$

3. Ydyrys A., Serbayeva A., Dossymbetova S., Akhmetova A., Zhuystay A., The effect of anthropogenic factors on rare, endemic plant species in the Ile Alatau, E3S Web of Conferences 222(2):05021 (2020) DOI:10.1051/e3sconf/202022205021

4. Ydyrys A., Abdolla N., Seilkhan A., Masimzhan M., Karasholakova L. Importance of the geobotanical studying in agriculture (with the example of the Sugaty region) E3S Web of Conferences, 222(1):04003 (2020) DOI:10.1051/e3sconf/202022204003

5. A.B. Akhmetova, N.M. Mukhitdinov, A. Ydyrys, A.A. Ametov, Z.A. Inelova, M. Öztürk, Journal of Animal and Plant Sciences, 28(5), 1400 (2018)

6. A. Begenov, N. Mukhitdinov, A. Ametov, S. Nazarbekova, A. Kuatbayev, B. Tynybekov, K. Abidkulova, A. Ydyrys, World Applied Sciences Journal, 30(1), 105 (2014)

7. T. Baidaulet, A. Ydyrys, M. Imanaliyeva, Zc. Askarova, G. Srailova, M. Murzakhmetova, S. Tuleukhanov, Effects of Almaty city ecological factors on students blood indices E3S Web of Conferences, 169(1):04005 (2020) DOI: $10.1051 / \mathrm{e} 3$ sconf/202016904005 
8. Yang Wei, Gang Li., IOP Conf. Series: Earth and Environmental Science, 170(3), 032154 (2018)

9. V.D. Bashirov, A.M. Balgynova, Merekekyzy Ardak and R.F. Sagitov, IOP Conf. Ser.: Mater. Sci. Eng., 560, 012037 (2019)

10. N.T. Tormanov, N.T. Ablayhanova, G.A. Tusupbekova, B.I. Ursheeva, A.O. Tangirbergenova, The effect of ambient temperature on the human blood cells Bulletin of KazNU (Biological Series), 3(68), 145 (2016)

11. G.A. Tussupbekova, S.T. Tuleukhanov, N.T. Ablaikhanova, Yu.A. Kim, A. Ydyrys, International Journal of Biology and Chemistry, 2(11), 83 (2018) 